\title{
The influence of defects at the steel/concrete interface for pitting corrosion initiation studied through X-ray Computed Tomography and image analysis
}

\author{
Emanuele Rossi ${ }^{1, *}$, Timo Nijland ${ }^{2}$, Oğuzhan Çopuroğlu ${ }^{1}$, Rob Polder $^{1,3}$ and Branko Šavija ${ }^{1}$ \\ ${ }^{1}$ Delft University of Technology, Faculty of Civil Engineering \& Geosciences - Department of Materials \& \\ Environment,Stevinweg 1, 2628 CN Delft, The Netherlands \\ ${ }^{2}$ TNO Buildings, Infrastructures and Maritime, PO Box 155, 2600 AD Delft, The Netherlands \\ ${ }^{3}$ RPCP, Fluwelensingel 106, 2806 CH Gouda, The Netherland
}

\begin{abstract}
Although corrosion of reinforcement is a well-known issue for the construction industry, there are still open questions about some fundamentals of corrosion in reinforced concrete. These points include, among others, which are the most sensitive locations of the steel/concrete interface for pitting corrosion to initiate and to propagate. In this study, X-ray computed tomography (CTscan) is used to characterize eight 20 -years-old reinforced concrete cores naturally deteriorated due to chloride-induced corrosion. The volume loss due to corrosion of the reinforcement was quantified through image analysis of CT-scans. The volume loss of the steel was found to be higher for steel rebars embedded in Portland cement specimens rather than in blended cement specimens. Furthermore, CT-scans revealed that the deepest and most frequent corrosion pits, as well as the consequent highest volume loss of steel, were present at the portion of the reinforcement closer to the outdoor environment and in proximity to air voids at the steel/concrete interface. As a consequence, the highest decrease of structural performance of the rebars would be likely localized at those locations. Therefore, the presence of interfacial air voids should be considered as relevant factor when assessing the risk of corrosion of reinforced concrete structures.
\end{abstract}

\section{Introduction}

Chloride-induced corrosion of steel reinforcement is a common cause of deterioration for reinforced concrete structures [1]. When assessing the risk of corrosion of structures, the critical chloride content $\left(C_{\text {crit }}\right)$ that causes corrosion initiation is one of the main parameters considered [2]. However, the tolerable chloride content for corrosion initiation is influenced by characteristics of the steel/concrete interface and of the concrete environment, such as by macro-pores, interfacial air voids and cracks [3-4].

Some studies reported that defects at the steel/concrete interface (SCI) are required for initiation of corrosion of the reinforcement [5-8]. When no interfacial imperfections are present, strong and dense contact between steel and concrete is reported to provide physical and chemical protection for corrosion of the reinforcement $[5,9]$. Therefore, the higher the number of interfacial defects, the lower the corrosion resistance [9, 10]. However, recent studies reported that defects at the SCI did not have any influence on corrosion initiation under certain environmental conditions [4, 11]. Furthermore, Angst et al. [4] observed by visual inspections that the location of corrosion onset did not coincide with the location of interfacial air voids. Although many studies have been conducted on the influence of interfacial defects for chloride-induced corrosion [4-12], on-going investigations and discussions on the topic highlights the importance to clarify if, and how, interfacial voids may affect initiation and propagation of corrosion of steel in concrete.

In this study, characterization of eight 20-year-old reinforced concrete specimens was conducted through $\mathrm{X}$-ray Computed Tomography (CT-scan) and image analysis. The main aim of this study was to observe and to quantify the depth and the amount of corrosion pits with regard to the presence of defects at the SCI and to the inside/outside exposed portion of the reinforcement. Also, the volume loss due to corrosion of reinforcement embedded in different concrete mixes after 20 years of natural exposure was quantified through image analysis.

\section{Materials and methodology}

\subsection{Specimen preparation and X-ray Computed Tomography}

Eight reinforced concrete cores were analyzed through $\mathrm{X}$-ray Computed Tomography (CT-scan). The cores were drilled out of 20-years-old prisms cast in 1998 by Polder et al. [13] with dimensions equal to $300 \mathrm{~mm} x$ $100 \mathrm{~mm} \times 100 \mathrm{~mm}$ (Figure 1). The prisms were cast with four different cement types (CEM I, CEM II/B-V, CEM III/B, CEM V/A), identical water/binder ratio (0.55) and

*Corresponding author: e.rossi@tudelft.nl 
they contained siliceous aggregates with a maximum diameter $\left(D_{\max }\right)$ of $8 \mathrm{~mm}$. The steel rebars were cast parallel to the concrete casting direction.

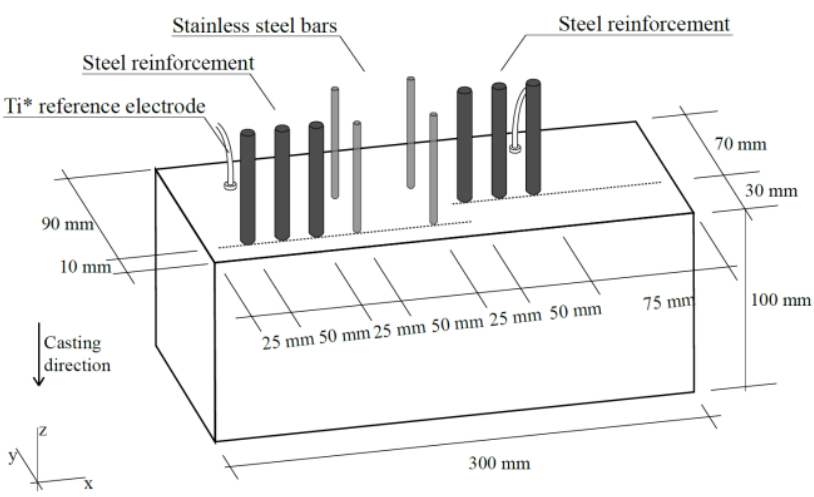

Fig. 1. Schematic representation of reinforced concrete prisms

The concrete compositions are summarized in Table 1.

Table 1. Mix proportions for each mix design (w/c of 0,55 ; $D_{\max }$ of $8 \mathrm{~mm}$ ) [13]

\begin{tabular}{|c|c|c|c|}
\hline $\begin{array}{c}\text { Mix } \\
\text { code }\end{array}$ & $\begin{array}{c}\text { Cement } \\
\text { content }\left(\mathbf{k g} / \mathbf{m}^{\mathbf{3}}\right)\end{array}$ & $\begin{array}{c}\text { Aggregate } \\
\text { content } \\
\left(\mathbf{k g} / \mathbf{m}^{\mathbf{3}}\right)\end{array}$ & $\begin{array}{c}\text { Admixtures } \\
(\% \text { by mass } \\
\text { of cement })\end{array}$ \\
\hline I & 287 & 1827 & 3.0 \\
\hline II/B-V & 280 & 1830 & 2.0 \\
\hline III/B & 286 & 1864 & 2.0 \\
\hline V/A & 279 & 1839 & 2.0 \\
\hline
\end{tabular}

The prisms were exposed to $3 \% \mathrm{NaCl}$ solution wet/dry cycles for the first 6 months after casting. Each cycle consisted of applying the solution of the front side of the specimens for 24 hours and let the specimens dry for 6 days at $20^{\circ} \mathrm{C}$ and $50 \%$ relative humidity (RH). According to previous research, at 26 weeks after casting the chloride content at the locations of the rebars $(10 \mathrm{~mm}$ depth) was higher than $2.5 \%$ by mass of cement for all the specimens analyzed in this research. Also, according to steel potential and corrosion rate measurements, corrosion initiation for the specimens analyzed in this study very likely occurred within the first year after casting [14]. After the exposure to wet/dry cycles with $\mathrm{NaCl}$ solution, the specimens were exposed unsheltered to the outdoor environment for around 18 years. From each prism, a 20-mm diameter concrete core was drilled embedding one single steel rebar which was cast with 10 $\mathrm{mm}$ of cover depth. Prior to drilling, the bottom side of the prism was marked with an arrow indicating the direction of the mould face, to keep track of which side was exposed to the outside environment (labeled as $\mathrm{N}$ direction). Cores were then labelled depending on their cement type, as reported in Table 2, which also includes the condition at which cores were observed before being tested. Cores cast with identical cement type (i.e. with same mix code) have been drilled out from different prisms with equal composition.

Table 2. Labels and condition of reinforced concrete cores before testing

\begin{tabular}{|c|c|c|}
\hline Label & Cement type & State of the specimen \\
\hline $\mathrm{I}-1$ & $\begin{array}{c}\text { CEM I } 32.5 \mathrm{R} \\
\begin{array}{c}\text { Portland } \\
\text { cement }\end{array} \\
\end{array}$ & $\begin{array}{l}\text { Surface cracks and rust } \\
\text { stains, heavily corroded }\end{array}$ \\
\hline $\mathrm{I}-2$ & $\begin{array}{c}\text { CEM I 32.5 R } \\
\text { Portland } \\
\text { cement }\end{array}$ & No signs of corrosion \\
\hline $\mathrm{I}-3$ & $\begin{array}{c}\text { CEM I } 32.5 \mathrm{R} \\
\text { Portland } \\
\text { cement }\end{array}$ & $\begin{array}{l}\text { Many surface rust stains, } \\
\text { modestly corroded }\end{array}$ \\
\hline II/B-V-1 & $\begin{array}{l}\text { CEM II/B-V } \\
32.5 \mathrm{R}(27 \% \\
\text { fly ash) }\end{array}$ & $\begin{array}{c}\text { Many surface rust stains, } \\
\text { modestly corroded }\end{array}$ \\
\hline III/B-1 & $\begin{array}{l}\text { CEM III/B } \\
\text { LH HS } 42.5 \\
\text { (75\% slag) }\end{array}$ & $\begin{array}{c}\text { A few surface rust stains, } \\
\text { lightly corroded }\end{array}$ \\
\hline III/B-2 & $\begin{array}{l}\text { CEM III/B } \\
\text { LH HS } 42.5 \\
\text { (75\% slag) }\end{array}$ & No signs of corrosion \\
\hline V/A-1 & $\begin{array}{c}\text { CEM V/A } \\
42.5 \text { (25\% fly } \\
\text { ash, } 25 \% \text { slag })\end{array}$ & $\begin{array}{l}\text { Surface cracks and rust } \\
\text { stains, heavily corroded }\end{array}$ \\
\hline V/A-2 & $\begin{array}{c}\text { CEM V/A } \\
42.5 \text { (25\% fly } \\
\text { ash, } 25 \% \text { slag) }\end{array}$ & $\begin{array}{l}\text { Surface cracks, no } \\
\text { observed rust }\end{array}$ \\
\hline
\end{tabular}

After drilling, cores were kept drying for 72 hours in a room at $20^{\circ} \mathrm{C}$ and $45 \% \mathrm{RH}$, then CT-scans were performed using a Phoenix Nanotom. Images were acquired at $150 \mathrm{kV}$ of transmission acceleration voltage with a spatial resolution of $20 \mu \mathrm{m}$. The total scanned height was around $45 \mathrm{~mm}$ starting at $10 \mathrm{~mm}$ from the top side of the core. Different components of each specimen (i.e. steel, corrosion product, air voids, cracks and concrete) were segmented based on their different grey scale values using the image analysis software Fiji. A typical CT-scan showing different phases of the material is shown in Figure 2.

\subsection{Volume loss quantification and corrosion pits distribution}

After segmentation, the volume of each steel rebar at the time of testing was quantified through pixel and voxel statistics according to Dong et al. [15]. The volume loss due to corrosion was determined as the percentage difference between the initial volume and the volume at the time of testing according to (1):

$$
V_{\text {loss }}=\left[\left(V_{0}-V_{20}\right) / V_{0}\right] * 100
$$

where $V_{0}$ is the initial volume of the reinforcement $\left(\mathrm{mm}^{3}\right)$ and $V_{20}$ is the volume of the reinforcement 20 years after casting $\left(\mathrm{mm}^{3}\right)$. 


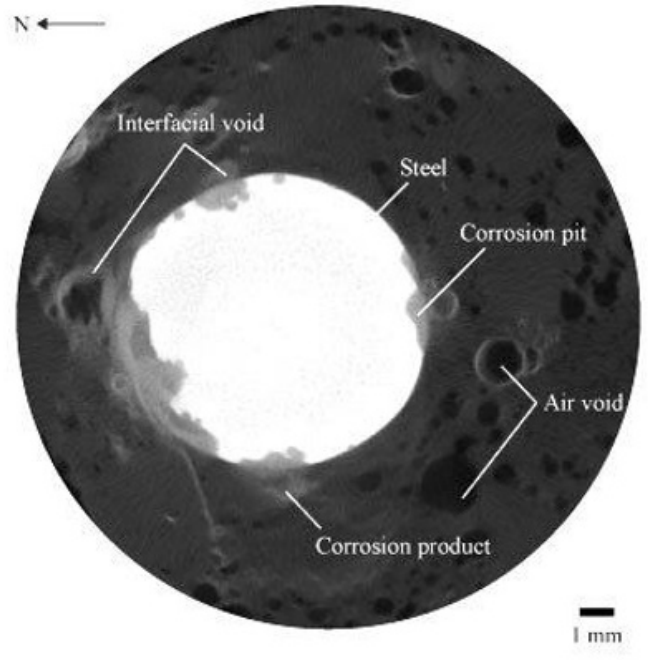

Fig. 2. CT-scan showing different phases (from I-1)

The initial volume of the reinforcement, $V_{0}$, was calculated through measuring the diameter of noncorroded portions of the specimens.

A selection of 2D CT-images was used to analyze the relation between corrosion pits, exposure side of the steel and presence of interfacial defects. For each CTimage, pit depths were clockwise measured at different angles from the center of the bar around $360^{\circ}$ with $30^{\circ}$ interval as conducted by Sun et al. [16], as shown in Figure 3. The depth of the pits, $d$, is measured (2):

$$
d=R-R_{0}
$$

where $R_{0}$ is the initial radius of the rebar and $R$ is the radius of the rebar 20 years after casting. The range between $180^{\circ}$ and $0^{\circ}$ clock-wise, $N$-direction, indicates the direction to the mould face (i.e. the portion closer to the outside environment). After measuring pit depths, they were divided in four groups depending on their orientation ( $\mathrm{N}$ - and S-direction) and if they were in proximity to air voids at the SCI or not: type 1 (T1, in orange) and type 3 (T3, in green) were representative for corrosion pits formed close to air voids at $\mathrm{N}$ - and $\mathrm{S}$ orientation respectively. Type 2 (T2, in yellow) and type 4 (T4, in blue) were representative for pits formed where the cement paste is dense at the SCI at both the orientations ( $\mathrm{N}$ - and $\mathrm{S}$-direction respectively). An example of this distinction is shown in Figure 3.
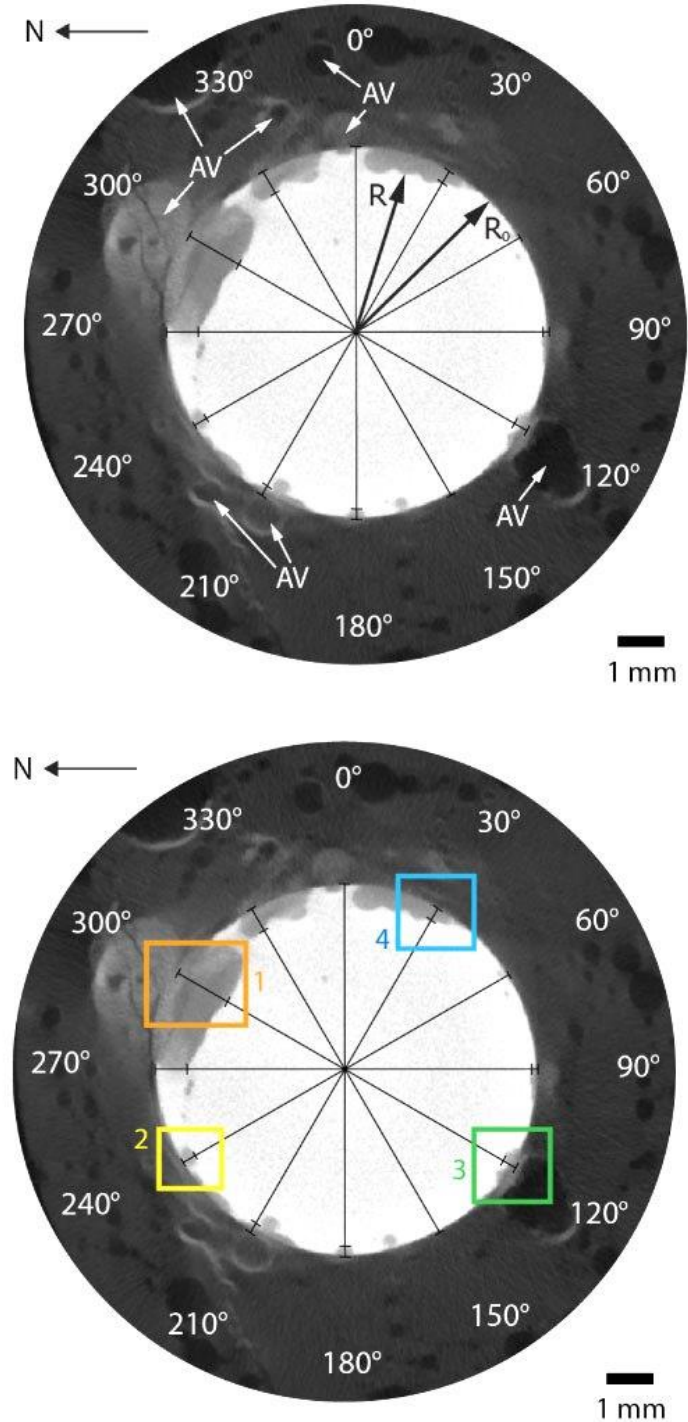

Fig. 3. (top) Depth and orientation of corrosion pits (AV=air voids). (Bottom) corrosion pits distinction: $\mathrm{N}$-oriented pit in proximity of an air void (type-1, orange); N-oriented pit coincident to dense cement paste at the SCI (type-2, yellow); $\mathrm{S}$-oriented pit in proximity of an air void (type-3, green); Soriented pit coincident to dense cement paste at the SCI (type4, blue). 


\section{Results and discussion}

\subsection{Steel volume loss due to corrosion}

The average volume loss of reinforcement due to corrosion is reported in Figure 4.

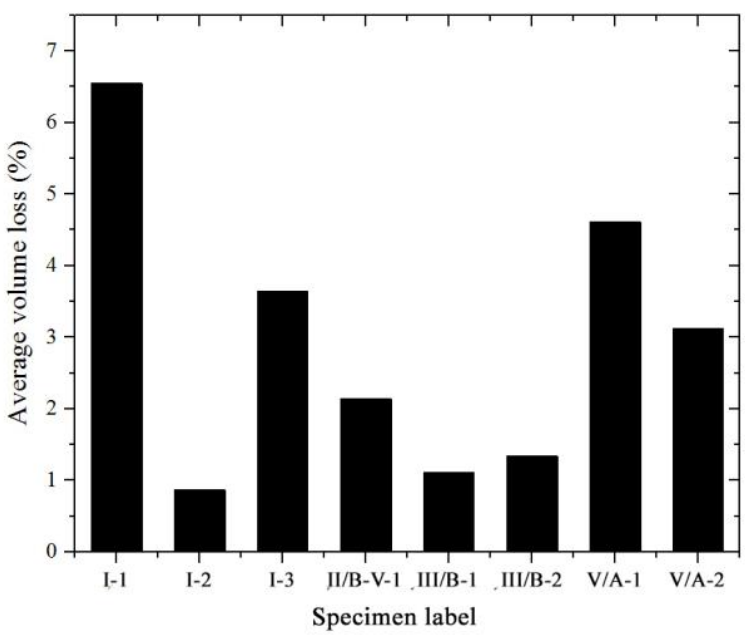

Fig. 4. Average volume loss (\%) of steel reinforcement due to corrosion after 20 years of exposure

On average, rebars embedded in blended cementconcrete had lower volume loss due to corrosion than those cast with OPC (Ordinary Portland Cement). Negligible volume loss was measured for CEM III/B specimens, equal to around $1 \%$ for both III/B-1 and III/B-2. Slightly higher average volume loss of around $2 \%$ was found also for II/B-V-1. The highest average volume loss for blended cement specimens was measured for V/A-1. However, surface cracks were noticed upon inspecting the specimen. Cracks probably allowed for more aggressive ingress of electrolyte and harmful agents, resulting in higher average volume loss than rebars embedded in blended cement-based concrete and especially than V/A-2, which was cast with identical cement type (i.e. CEM V/A) but lost 3\% of steel volume because it was less cracked than V/A-2. Higher variability was observed for rebars embedded in CEM I concrete since volume loss of around $6.5 \%, 0.9 \%$ and $3,5 \%$ was measured for I-1, I-2 and I-3, respectively.

Concrete cast with blended cement had higher corrosion resistance than that cast with OPC, probably thanks to the denser microstructure of the former ones, which is known to improve both the chloride penetration resistance and the resistivity of the mix [14]. Similar improvements can be achieved by lowering the water/binder ratio of the concrete [4]. Interestingly, I-2 had the lowest average volume loss of all the specimens, equal to around $0.9 \%$. Since this volume loss is significantly lower than that of other rebars embedded in specimens cast with OPC, and they were exposed to the same environmental conditions, doubts were raised about the composition of I-2. Indeed, during the 20 years after casting, the specimens were re-located and some of them might be mis-labeled. Specimens were then re-identified non-destructively, as described more in detail elsewhere [17]. It might be the case that the composition of I-2 was not identified accurately, and that its water/binder ratio would be lower than 0,55 . Since lower water/binder ratio improves the corrosion resistance of concrete [3], it would explain why I-2 had, unexpectedly, the lowest volume loss of reinforcement.

It must be specified that volume losses of steel quantified through CT-scan analysis could be misestimated due to segmentation inaccuracies and resolution limitation, as reported by others [18]. Nevertheless, since specimens were subjected to equal image acquisition and processing, potential drawbacks related to compare one test to each other are considered negligible.

\subsection{Corrosion pit depths, orientation and relation with interfacial defects}

The relation between corrosion pit depths, orientation and presence of interfacial defects is shown in the boxplot of Figure 5.

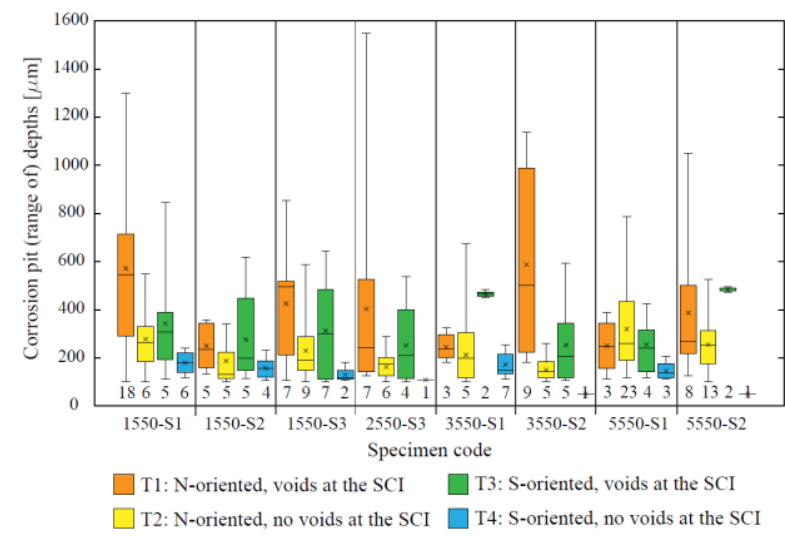

Fig. 5. Range of depth of types of corrosion pits $(\mu \mathrm{m})$ with outside/inside orientation and proximity to concrete defects at the SCI. The top, middle and bottom line of the boxes correspond to the 75-, 50- and 25-percentile value ( $\mathrm{x}_{75}, \mathrm{x}_{50}$ and $\mathrm{x}_{25}$ ) respectively. The whiskers show the minimum and maximum values. The number below each series represents the number of pits of each type per specimen.

Comparing $\mathrm{T} 1$ to $\mathrm{T} 2$ and $\mathrm{T} 3$ to $\mathrm{T} 4$, the influence of air voids at the SCI on corrosion pit depth can be analyzed. $\mathrm{T} 1$ and $\mathrm{T} 3$ are generally deeper than $\mathrm{T} 2$ and $\mathrm{T} 4$ respectively. This statement is not valid for III/B-1 and V/A-1 only. However, in the former case only a few air voids were present at the SCI, hence compromising the comparison with other specimens, while V/A-1 was heavily cracked, which probably led to more generalized corrosion along the steel portion oriented towards the outside environment (i.e. N-oriented side). 
Comparing $\mathrm{T} 1$ to $\mathrm{T} 3$ and $\mathrm{T} 2$ to $\mathrm{T} 4$ the influence of the steel orientation can be analyzed. For most of the specimens, $\mathrm{N}$-oriented pits are more and deeper than $\mathrm{S}$ oriented pits, likely due to more frequent exposure to wet and dry cycles of the electrolyte and higher ingress of harmful agents (i.e. chlorides and carbon dioxide) due to the closer proximity of this side to the outside environment. On average, the combination of exposure to the outside environment and presence of interfacial air voids (i.e. T1 pits) revealed to be the most aggressive conditions for corrosion pits to firstly form and then to grow; on the contrary, the S-oriented side of the reinforcement revealed to be the least corroded side, particularly when no air voids at the SCI were found (T4). To give a better understanding of the occurrence of pits in proximity to interfacial voids, 3D renders of the front side of the corroding rebars with and without highlighted corrosion product around the reinforcement are shown in Figure 6. Corrosion pits in proximity to interfacial voids are indicated by black arrows. From Figure 6 it is qualitatively visible that the deepest corrosion pits occur where interfacial voids are present. This influence might not be clearly marked for the most corroding rebars (i.e. I-1 and V/A-1), for which the whole front side is heavily corroding. On the contrary, deep corrosion pits occurring at those locations seem obvious for the other specimens, especially for I-3, II/B$\mathrm{V}-1, \mathrm{III} / \mathrm{B}-2$ and V/A-2. Interestingly, these specimens seem to be subjected to relatively deep corrosion pits occurring in proximity to interfacial voids that are 5-15 $\mathrm{mm}$ apart from each other. Around the deep pits, reinforcement looks slightly corroding.

In this study it was observed that defects at the steel/concrete interface (i.e. macro-voids) appear to be

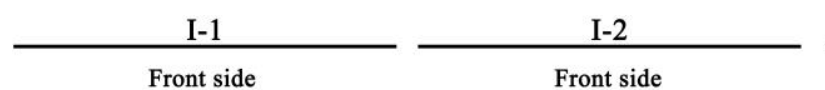

$\begin{array}{ccc}\text { I-3 } & \text { II/B-V-1 } \\ \text { Front side } & \text { Front side } \\ \text { Corroding steel Corrosion product } & \text { Corroding steel Corrosion product }\end{array}$

Corroding steel Corrosion product Corroding steel Corrosion product Corroding steel Corrosion product Corroding steel Corrosion product
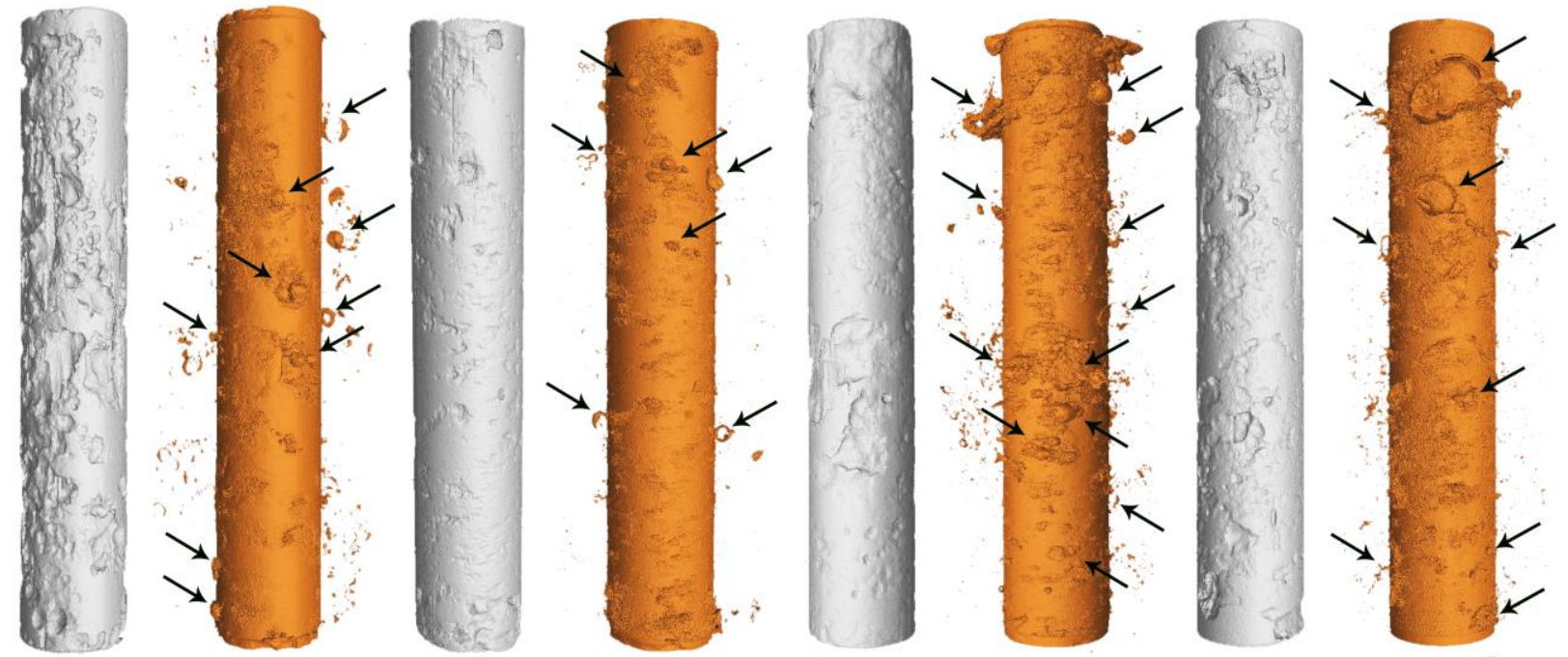

$5 \mathrm{~mm}$
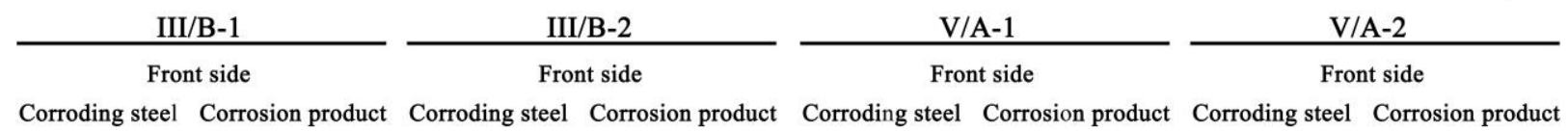

Corroding steel Corrosion product Corroding steel Corrosion product
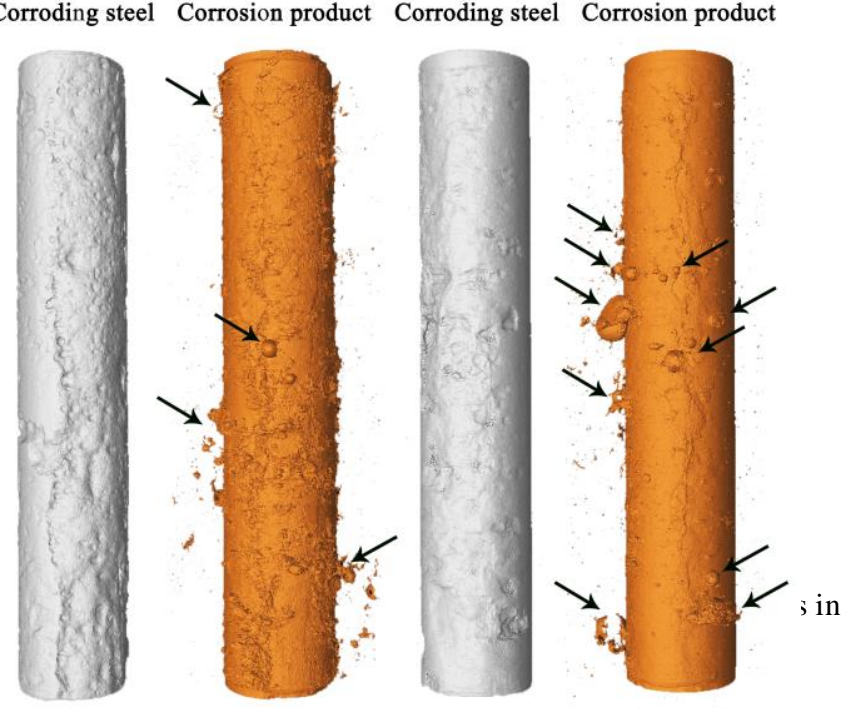

$5 \mathrm{~mm}$

Fig. 6. Render of corroding reinforcement (grey) and corrosion product around the steel rebar (brown). Black arrow indicates pits in proximity to interfacial air voids. Only the front side of the rebar is reported. 
the most preferential locations for corrosion pits to be found. Moreover, pits formed in proximity to interfacial voids are on average deeper than those formed where the cement paste is dense and compact around the reinforcement. Occurrence of pits in proximity to interfacial voids is also confirmed by Environmental Scanning Electron Microscope (ESEM) images of polished sections of the SCI, of which an example is reported below (Figure 7).

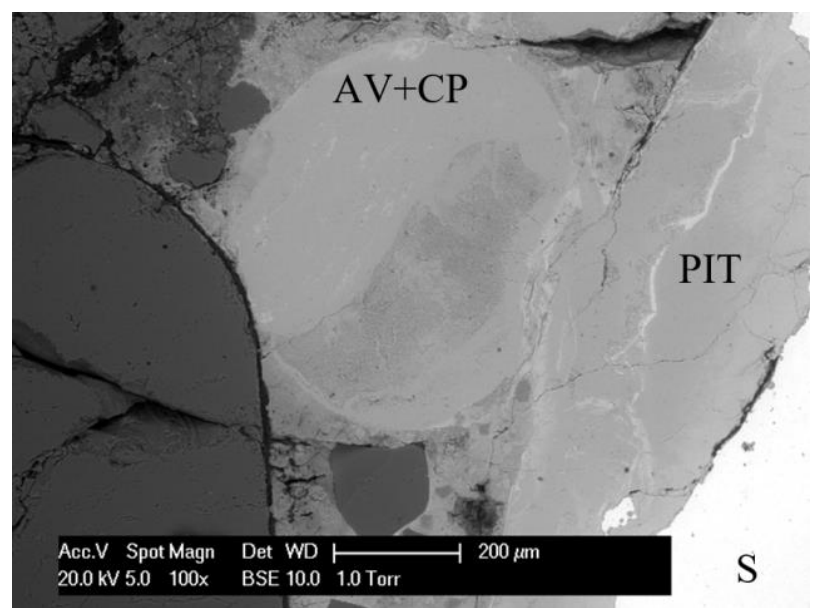

Fig. 7. Corrosion pit (PIT) in proximity of an interfacial air void filled by corrosion product $(\mathrm{AV}+\mathrm{CP})$. $(\mathrm{S}=$ steel rebar $)$

The results of this study are in agreement with what was pointed out by Glass et al. [10] about the inversely proportional relation between corrosion resistance and percentage of interfacial voids. Corrosion initiation in proximity to interfacial voids was recently observed by Van Steen et al. [18], which localized anodic-induced corrosion initiation sites through CT-scan and acoustic emission. Once initiated, corrosion pits tent to propagate at those locations. This fact may probably be caused by the higher availability of oxygen and electrolyte present at the void locations as well as by their accommodating open space, which results in no constraint from the surrounding concrete that might block oxide formation [19]. A similar mechanism was observed by Savija et al. [20] when monitoring the progress of anodic-accelerated corrosion of concrete cores through CT-scan, during which non-uniformities of the corrosion layer and consequent higher localized volume loss occurred in proximity to interfacial air voids. However, the rebars of the studies of Van steen et al. [18] and Savija et al. [20] were subjected to anodic-accelerated corrosion, which might influence where corrosion would initiate.

Based on the results of this study, interfacial air voids are the locations where corrosion propagates the most, resulting in higher localized steel volume loss in proximity to interfacial defects. This finding might be related to the influence that interfacial voids might have on either corrosion initiation or corrosion propagation. On the one hand, it might be assumed that the deepest pits are those that initiated the earliest, hence the results of this study would suggest that interfacial voids would be the most sensitive locations for corrosion initiation. This mechanism would presuppose that the corrosion rate does not depend on the local characteristics of the steel/concrete interface, and that would be constant for any corrosion pit. However, it is likely that the corrosion rate at pits would be locally influenced by, for instance, the availability of oxygen, the electrolyte and the local chloride content. Hence, concluding that interfacial voids are the most sensitive locations for corrosion initiation might be inaccurate. More continuous observations of corrosion initiation are needed to better understand this mechanism. On the other hand, this study showed unequivocally that corrosion propagated the most in proximity to interfacial voids. This mechanism might be completely unrelated to the influence that interfacial voids might have on corrosion initiation. In other words, corrosion could initiate anywhere the chloride content is higher than the critical threshold, regardless of the presence of interfacial defects. Interfacial voids might then be the locations where corrosion pits would propagate only because, for instance, no physicochemical constraint would be provided by the surrounding matrix. Propagation of corrosion in proximity to interfacial voids might also mitigate the growth of neighbouring pits due to, for example, the cathodic flow occurring in proximity to the growing pit. This mechanism would result in deep pits localized where interfacial defects are present, and no corrosion pits in the surroundings, as qualitatively suggested by Figure 6. To clarify the influence that interfacial air voids have on both corrosion initiation and propagation, more investigations are encouraged. Nevertheless, the results of this study suggest that interfacial air voids should be considered detrimental factors for corrosion resistance of reinforced concrete.

In this study, the most sensitive rebar side to corrosion was that exposed to the outdoor environment, contrary to what has been reported by other authors [4, 21]. Angst et al. [4] observed that in rebars cast perpendicularly to the concrete casting direction, the bottom side of the steel was the most corroding due to the higher amount of localized defects caused by plastic settlement and bleeding. However, the rebars analyzed in the present study were placed parallel to the casting direction, not causing localization of defects at one specific side. Since the quality of the two steel sides could be considered ideally the same, it is reasonable that the outer portion of the steel would be more sensitive to corrosion on average, due to, for instance, higher availability of the electrolyte, more frequent wet/dry cycles and higher content of harmful agents coming from the outside environment. It must be specified that the rebars analyzed in this study had 10 $\mathrm{mm}$ of cover depth, which is not very representative for good practice. It is very likely that for thicker cover depth (i.e. $30 \mathrm{~mm}$ ), the influence of the exposure side would not be so marked because of the higher physical protection provided. In that case, the preferential locations for corrosion to propagate would probably be in proximity to interfacial defects regardless of the exposure side of the steel reinforcement. 


\section{Conclusions}

From the present study, the following major conclusions can be drawn:

- After 20 years of natural exposure, the volume loss of reinforcement embedded in OPC concrete was on average higher than that of rebars embedded in blended cements-concrete,

- The deepest corrosion pits were observed at the portion of the steel exposed to the outside environment and in proximity to interfacial defects (i.e. air voids), which appeared to be the most preferential locations for corrosion propagation,

- In cracked concrete (i.e. 5550-S1) whole side of the steel oriented towards the crack was corroding, suggesting a transition from pitting to more distributed corrosion,

In the authors' opinion, the use of X-ray Computed Tomography could very much help to better understand some fundamentals of corrosion in reinforced concrete, such as monitoring the corrosion initiation sites during time of more recently cast specimens. For future research, understanding where corrosion sites initiate would be valuable for both the scientific community and the industry since it would help to be aware of what are the potentially most sensitive locations for corrosion to happen, with consequent more specific inspections and effective maintenance.

The authors would also like to thank Mr. Arjan Thijssen for his assistance with the X-ray Computed Tomography experiments.

\section{References}

1. L. Bertolini, B. Elsener, P. Pedeferri, R.B. Polder, Wiley-VCH Verlag GMBH \& Co., Weinheim (2004)

2. U. Angst, B. Elsener, C.K. Larsen, Ø. Vennesland, Cem Concr Res, 39, 1122-1138, (2009)

3. U. Angst, M. Geiker, A. Michel et al., Mater Struct, 50, 143, (2017)

4. U. Angst, B. Elsener, C.K. Larsen, Ø. Vennesland, Corros Sci, 53, 1451-1464, (2011)

5. T. Soylev, R. Francois, J Mater Civ Eng, 17, 447455, (2005)

6. T. Yonezawa, V. Ashworth, R. Procter, Corros Eng 44, 489-499, (1988)

7. T. Mohammed, N. Otsuki, M. Hisada, ACI Mater J, 96, 154-159, (1999)

8. T. Mohammed, N. Otsuki, H. Hamada, T. Yamaji, ACI Mater J, 99, 149-156, (2002)

9. C. Christodoulou, G. Glass, Australasian Corrosion Association 2012 Annual Meeting, 159, (2012)

10. G. Glass, B. Reddy, L. Clark, Const. Mat, 160, 155164, (2007)

11. U. Angst, PhD thesis, NTNU, Trondheim, (2011)
12. T. Mohammed, N. Otsuki, H. Hamada, J Mater Civil Eng 15, 460-469, (2003)

13. R.B. Polder, P. Russo, 98-BT-R1664, TNO Building and Construction Research, Rijswijk, TNO, (1998)

14. R.B. Polder, W.H.A. Peelen, Cem Concr Compos, 24, 427-435, (2002)

15. B. Dong, W. Ding, S. Qin, G. Fang, Y. Liu, P. Dong, S. Han, F. Xing, S. Hong, Constr Build Mater 168, 11-20, (2018)

16. H. Sun, D. Zhao, Y. Gu, S. Memon, Z. Ren, B. Liu, X. Zhang, F. Xing, D. Li, Constr Build Mater, 143, 24-32, (2017)

17. J. Pacheco, MSc thesis, Materials\&Environment, TU Delft, (2010)

18. C. Van Steen, L. Pahlavan, M. Wevers, E. Verstrynge, Constr Build Mater, 197, 21-29, (2019)

19. T.A. Soylev, R. Francois, Cem Concr Res, 33, 1407-1415, (2003)

20. B. Savija, M. Lukovic, S.A.S. Hosseini, J. Pacheco, E. Schlangen, Mater Struct, 48, 2043-2062, (2015)

21. U. Angst, C.K. Larsen, Ø. Vennesland, B. Elsener, in: P. Castro-Borges, E.I. Moreno, K. Sakai, O. Gjørv, N. Banthia (Eds.), CONSEC'10 6th Int. Conf. on Concrete under Severe Conditions, Environment and Loading, 1, Taylor \& Francis, London, 359-366, (2010) 